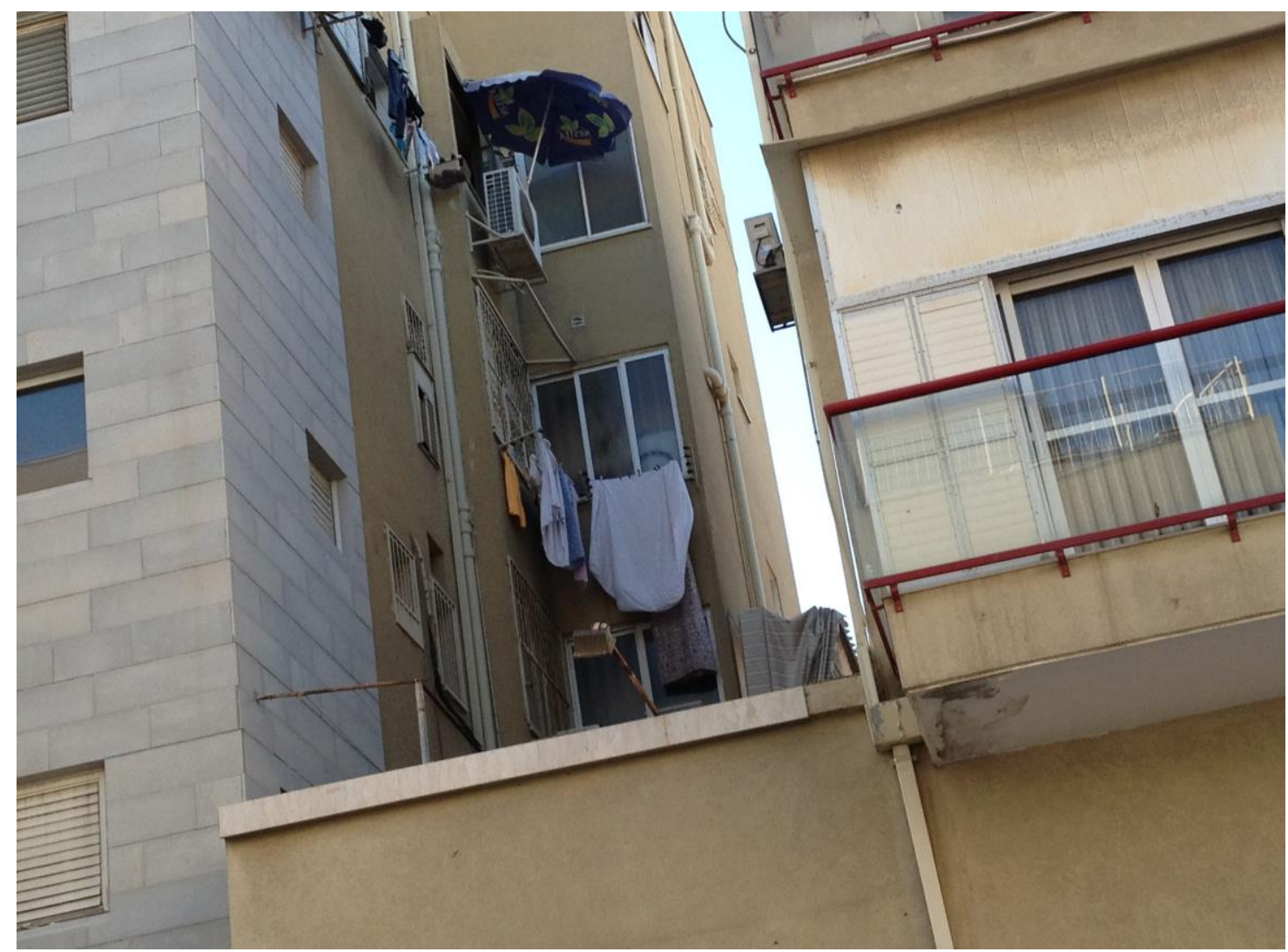

Source: Elena Siemens

\title{
Clothes Lines
}

Elena Siemens and Christine Wiesenthal University of Alberta

This collaboration, featuring poetry by Christine Wiesenthal and photography by Elena Siemens, connects domestic spaces to the social, public and commercial sphere of the street: to relationships, traffic, gossip, and sundry forms of "dirty laundry." In his essay on "Naples," Walter Benjamin states: "Porosity is the inexhaustible law of the life of this city, reappearing everywhere" (170). "Buildings and actions," he explains, "interpenetrate in the courtyards, arcades, and stairways. In everything they preserve the scope to become a theatre of new, unforeseen constellations" (169). He adds: "The stamp of the definitive is avoided" (169). This unique characteristic of Naples, its porosity, also surfaces in the "unforeseen constellations" of Wiesenthal's The Laundry Cycle, and Siemens' images of Tel Aviv. 


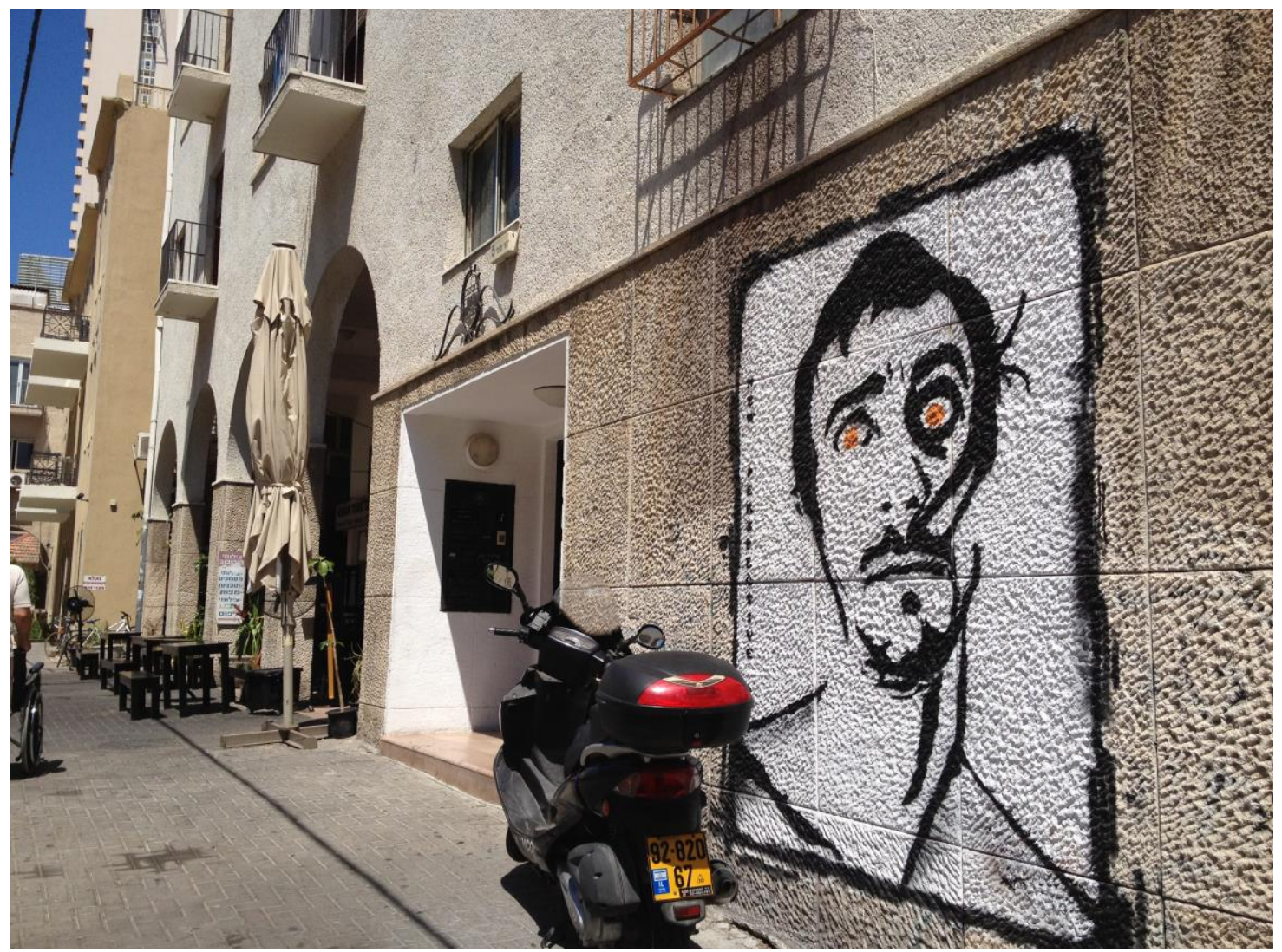

Source: Elena Siemens

From "The Laundry Cycle"

\section{Blues}

If these tests fail, depend only on an expert. You will save money, time and worry by calling a reliable service organization for a man who knows your appliance thoroughly.

-Home Laundry Guide

what is this weakness that washes over me as I sort through the blues always make me think of the sight of his denim clad hips sauntering along in slim cut jeans jeans old jeans good jeans his jeans my jeans a combination I like to fantasize about pants a couple pair crumpled in a heap tangled legs pockets peeled inside out in haste slip in four socks and some lightly scented soap like $A B C$ things get out of hand though and the agitator starts churning my gut to slush sucks me into his spin and puts me through the wringer till I find myself all washed up and hung up and strung out on a long thin line or two flap flap flapping on about a load of nothing at all can console me now as Dinah Washington sings I'm seeing red and feeling blue/holding my breath waiting for you sucker just can't wait to see him again can you maybe get in the last lick this time breezing along out of the blue give him a smack on the cheek a smart wet one too 


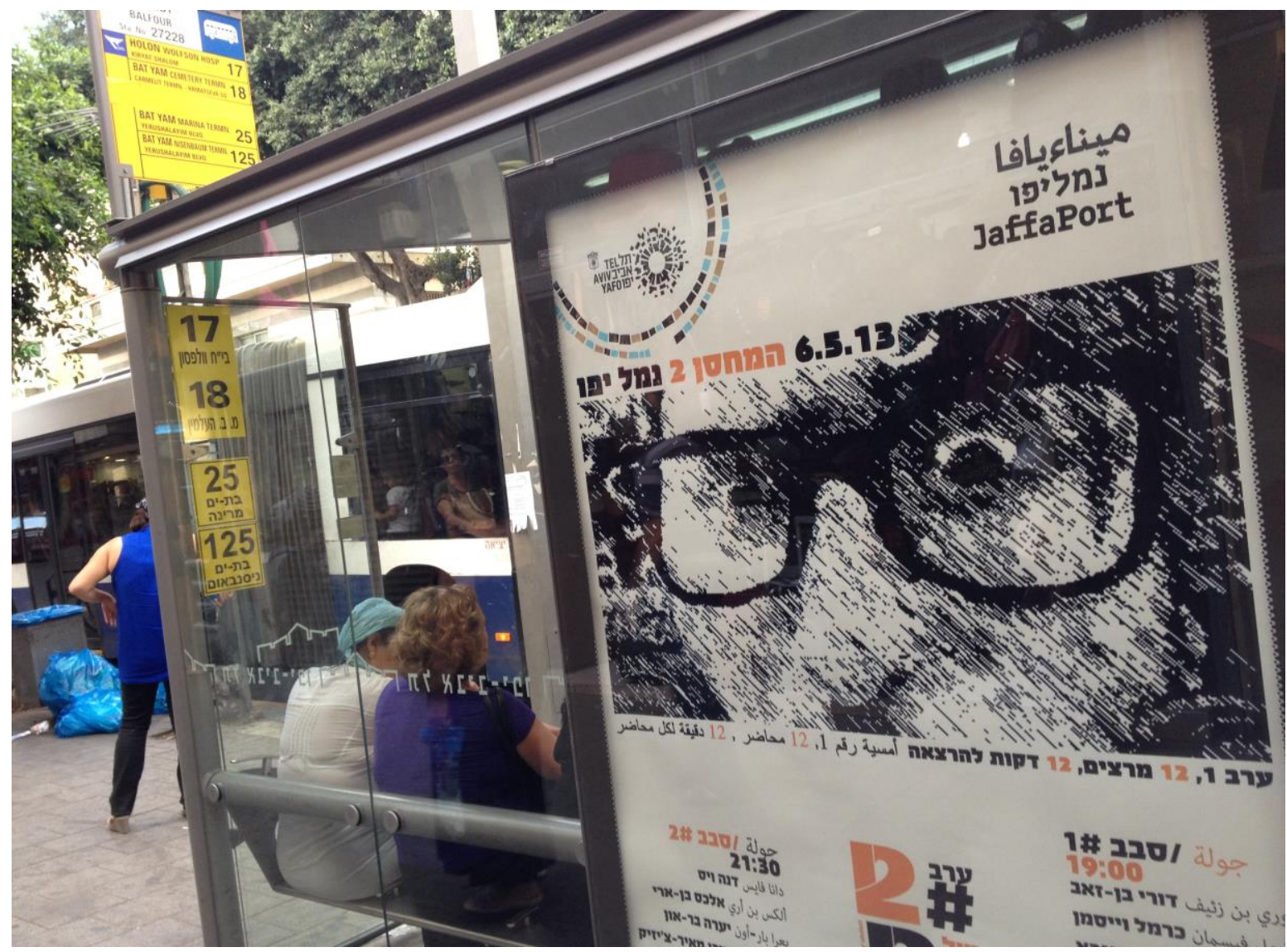

Source: Elena Siemens

\section{colors}

Calypso learns of Dr. Jeremy Wright's infidelity when she opens a letter meant for Polly on this week's episode of The Bold and the Beautiful.

\section{-Weekly Soap Opera Digest}

there will always be stains you can bet your babushka on that one yet must admit ink blood sap grass gum grease wax wine lipstick yeh that must be mine crayon chocolate mud rust beet juice can actually look pretty artful when run into other jelly bean bright colors all jumbled up in the basket easter magic like no how to make them come clean in cold hard water is the real problem is the lye in the soap which is basically caustic soda and hell if you get it on your hands you're a goner if you happen to have sensitive skin that is all those heavy duty chemical reactions require a science if you want to do it right you need to know all about solvents and deposits ammonia and alkaline chlorine and corrosion inhibitors in any case a good acid enzyme that eats up dirt which is to say launders it can be hard to find as a last resort I recommend you read the bints on dyeing section of any reputable 


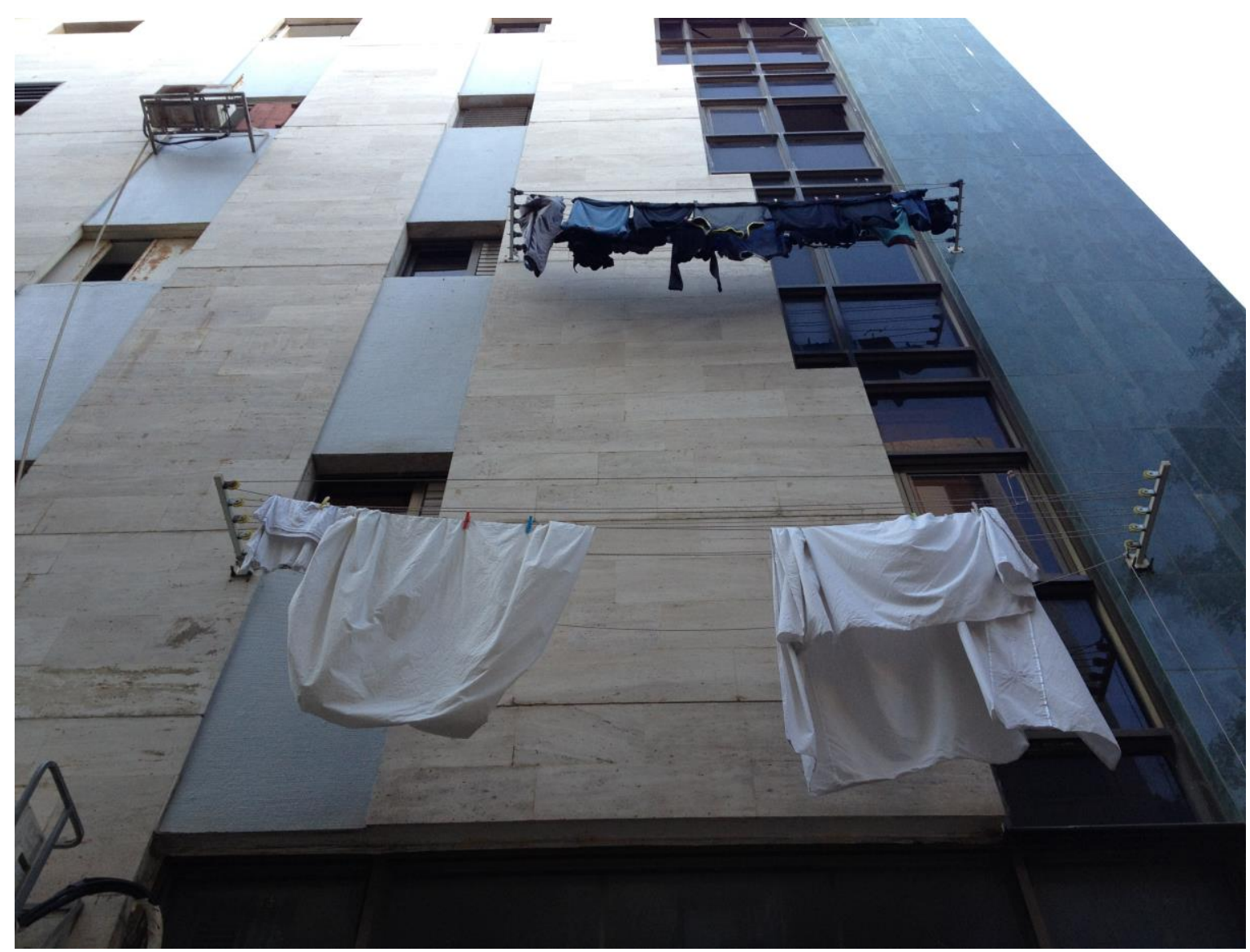

Source: Elena Siemens

home laundry guide believe me it's no snap no such thing as just reaching out for a good stiff shot of Wisk or Viva or Arctic Power when you run into a real beauty of a stain just Shout it out won't work either sorry I've tried your true colors you hear me loud and clear just don't come flying back slambang through 
TranscUlturAl, vol. 6.1 (2012), 92-96.

http://ejournals.library.ualberta.ca/index.php/TC

\section{REFERENCES}

Benjamin, Walter. "Naples.” One Way Street and Other Essays. London: Verso, 1985.

Wiesenthal, Christine. “The Laundry Cycle.” Instruments of Surrender. Ottawa: Buschekbooks, 2001. 